\title{
The Study of Regional Teacher Training Mode in the Environment of Guangdong Education Cloud Streaming
}

\author{
Zuyuan $\mathrm{Ma}^{1, \mathrm{a}}$, Yubing $\mathrm{Niu}^{2, \mathrm{~b}}$, Yi Dai ${ }^{3, \mathrm{c}}$ \\ ${ }^{1,2}$ Zhuhai Radio and TV University, Zhuhai, Guangdong, China \\ ${ }^{3}$ Zhuhai Education Bureau, Zhuhai, Guangdong, China

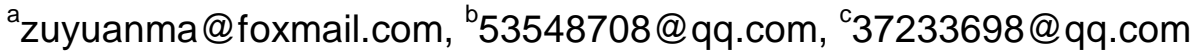

\begin{abstract}
Keywords: Guangdong Education Cloud, Guangdong Education Cloud Streaming, video cloud service, teacher training, video interaction analysis
\end{abstract}

Abstract. Along with the rapid development of video technology, the construction and application of video teaching resources advance astoundingly. Video resources offer more and more support to education while penetrate more and more deeply into it. The study of video resources helping teacher training spreads throughout the country. Traditional video-based teacher training has the disadvantage of low efficiency of resource sharing, de-contextualization, poor social interaction and poor process guidance, etc. The appearance of new technologies, such as big data, cloud computing, offers new opportunities to address these issues. Guangdong Education Cloud provides an open, interactive, scalable video cloud service of education. It supports real-time interactive live classroom, teacher online classroom, online training, collaborative education research and other typical applications. This paper discusses the teachers' information technology training and practice based on Guangdong Education Cloud public service platform in the trial plot of Zhuhai. The discussion draws to five new modes of teacher training with the support of Guangdong Education Cloud Streaming from the perspective of individual training and group training.

\section{Background}

Along with the penetration of information technology into the traditional classroom teaching, learning and using educational technology has become an irreversible trend. In 2013, in order to implement the general appealing of national education informationization, and to enhance the teacher's ability of applying information technology, the Ministry of Education decided to launch the project of enhancing the national primary and secondary school teachers' ability of applying information technology, and proposed the establishment of the standard system of teachers' ability of applying information technology, so as to promote the effective application of information technology in classroom teaching and daily work. More and more attention are paid to the study of how teachers use information technology to abtain, manage, sort and use information to promote teaching level, improve teaching process and guide students to learn information technology. The training to improve teachers' ability of using information technology becomes an essential part of education informationiztion construction.

In recent years, great achievements have been made through various information technology training among teachers all over the country. While the video technology develops rapidly, using teaching video in teachers training becomes a hotspot of educational study. The convenient and flexible video-based teacher training solves the problem of time arrangement, location and high training cost. It also erases the interruptive influence to classroom teaching caused by traditional live demonstration training mode. However, the traditional video-based training also has the disadvantage of watching the class passively, poor group cooperative interaction, de-contextualization of resources, and lack of effective guidance in the process of training, etc.. The emergence of cloud computing, interactive video technology and other new technology makes cloud streaming media become increasingly widespread in the field of teachers' training and teachers' professional development. The new technology provides good opportunities and conditions to solve the above problems. This paper discusses the teachers' learning and practice of information technology based on Guangdong Education Cloud project in Zhuhai, and 
analyses the training model supported by the cloud streaming media based on Guangdong Education Cloud Streaming.

\section{Literature Review}

The study of video-based teachers' learning can be traced back to the Micro-teaching in the United States in 1960s. Later, people carried out in-depth research and practice of Micro-teaching in Australia, the United Kingdom, Japan, China, South Africa and so on. Besides microteaching, the use of video sites and remote training platform in teacher training become an important way to promote teachers' professional development in the Internet era. NCREST (Nation Center for Restructuring Education, Schools and Teaching) in Columbia University has developed a digital video display website, providing the videos of two novice teachers, an experienced teacher and an educator of teachers to guide learners to learn from practice. Stanford University opened English Curriculum and Teaching website, providing the well-designed classroom teaching video and the associated text information for preservice teachers. The website guides the preservice teachers to watch the video cases of the experienced teachers, and helps them to integrate the teaching methods and strategies into their own teaching practice ${ }^{[1]}$.

At present, the study of teacher's using videos to learn things can be divided into 3 aspects: how do the videos support teachers' learning, how do the teachers learn from videos and how do different video materials affect teachers' learning ${ }^{[2]}$. A number of institutions in China have made positive attempts in video-based teacher training, such as, Outstanding Teachers' Demonstration Videos project by People's Education Press, Teachers Distance Training Project by the National Primary and Secondary School Teachers Continuing Education website, teachers' distance training based on classroom teaching video cases by the Central Audio-Visual Education Center etc.. The domestic scholars have done a lot of research on the meaning, strategy, feasibility and effectiveness of video services in teachers' professional development. Lei Gang (2011) summarizes three ways of using video resources in teacher training: constructing teacher training video resource library to promote the sharing and integration of high quality education resources; constructing $\mathrm{VOD}$ (video-on-demand) platform to promote teacher's personalized and professional development; constructing DVB(digital video broadcast) platform to expand the field of teacher knowledge ${ }^{[3]}$. Sun Mo (2011) discusses the role of classroom teaching video case in the teacher network training and puts forward strategies to guidance teachers to promote professional development through case observation, raising questions, discussions and exchanges, self-learning and self-guidance ${ }^{[4]}$. Gu Lingyuan and others explored the application of classroom teaching video cases in school-based teacher training and prove its effectiveness ${ }^{[5]}$.

In recent years, the study of video-based teacher learning has made important progress in foreign countries. People's attention turns from the early external teaching behavior to teachers' cognitive change and the improvement of classroom practice. Researchers build hypermedia learning environment, develop video collaborative analysis tools and a variety of learning activities based on theory and technology to promote teachers learning, and use video analysis to evaluate teachers' knowledge and skills ${ }^{[6]}$. Rosaen's team (2008) compared the teaching reflection mode based on the video analysis to the mode based on memory. They found that the former allowed teachers to write more targeted evaluation with more attention to students rather than to their own. Domestic scholar Wang Mei (2011) led teachers into in-depth observation of the classroom teaching and learning activities through the research of video, promoted teachers' analysis and changing of the structure of on classroom activity from the perspective of students' participation, so as to further explore optimized design of mini course and teaching ${ }^{[7]}$. Chen Xiu (2012) applied video analysis tools into Micro-teaching skills evaluation. She trained undergraduate normal students to make teaching reflective commentary on their microteaching video with software NAVIL to refine reflection and self-assessment ${ }^{[8]}$. Li Jing (2012) found that video analysis can help teachers describe their teaching 
behavior accurately and meticulously, and find out the hidden phenomenon and specific problems more easily ${ }^{[9]}$. Lv Wenhui (2013) put forward a new model of school-based new teacher training based on the reflection of classroom teaching video recordings. Sun Zhong and Ma Yuhui (2013) put forward the method of multivariate analysis of video cases, and applied it into the novice teachers training, which significantly enriched the the reflection angle of the novice teachers' professional development, and improve the novice teachers' teaching philosophy effectively ${ }^{[10]}$.

However, the effect of video-based and video analysis-based teachers' learning and is still doubtful. Firstly, video presentation itself is not equal to the occurrence of learning and reflection process. Watching classroom teaching videos can't directly constitute the effective situation to promote teachers learning ${ }^{[11]}$. If is the teacher has no or only a small amount of video analysis experience, he/she may not have access to insights and perspectives only by watching classroom videos ${ }^{[12]}$. Secondly, the lack of experts' online guidance and real-time interactive guidance will lead to the absence of many social attributes of education, and the learning effect is difficult to track continuously. Thirdly, learning materials are lack of situationality, and the supporting resources and materials of the video are not enough ${ }^{[13]}$. Both form the barriers for teachers to resonate with the video content., it is difficult Video cases should include the video itself and other teaching related information, together with the teaching theory, learning support system related to the video ${ }^{[14]}$. The video cases plus the carefully designed video research activities can provide great convenience for teachers to do analysis to the videos ${ }^{[15]}$. Fourthly, the strength of group study need be enhanced. Teacher learning is a typical process of development of individuals and groups. With the rise of the new generation of information technology such as mobile Internet, the Internet has a high speed development in the interactive, group and social aspects. At present, the teacher learning environment do not have a systematic consideration of the theory of group learning in a certain network learning environment. The group learning is still "technology driven" rather than "application driven". The common problem of teachers' group learning activities is: the lack of instant interaction and poor collaboration, which leads to passiveness and temporality of the learning.

\section{Cloud Video Services Bring New Opportunities to Video-based Teacher Training}

As the cloud computing and video interactive technology develops quickly, cloud video comes into people's field of vision. Cloud video services have the advantage of being easy to use, interactive, collaborative and the like. Its main application is in the video conference, network video, IPTV and other fields. It is video conference that offers more in-depth services on education and teaching. Traditional video conference system is complex and expensive, and needs special network and IT support. Its support to group meetings is not relatively weak. Cloud video conference is a visual, efficient, timely, low-cost remote communication tools. This new application of information technology has been applied in teaching, collaboration, management and other aspects, including remote conference and training, remote interactive teaching, remote viewing and evaluation, cross-regional cooperation, online streaming media teaching ${ }^{[16]}$. The video support platform of Peking University provides a full range of video conference services for teachers and students. It is widely used in scientific research cooperation, teaching management, and the innovation of teaching and enrollment $^{[17]}$. Shaoxing carried out Video Cloud Construction Project, which combined education promotion campaigns and video network technology. The project contains a variety of publicizing campaigns, such as a hundred Intelligent Youths, a hundred Young Booklovers, various excellent schools and excellent lessons, selected campus stories, etc. ${ }^{[18]}$. Video collaboration technology based on cloud has also attracted much attention. The world's top five universities are using Polycom video collaboration technology to carry out distance education. In this way, these universities break the traditional teaching pattern and build up a new teaching model ${ }^{[19]}$.

Domestic research on cloud video is mainly about the concept, prospect and technology of cloud video. 
It is still in its infancy. There are few studies on teachers' training based on Cloud Video Services. Fortunately, the emergence of cloud video services brings opportunities for the reform of traditional video-based teacher training. Cloud video services can meet the needs of large-scale video-based teacher training, construct the group interaction environment for teachers' training, and provide video analysis tools, as well as a series of high-quality video resources. The practice of regional teacher training using cloud video services is relatively rare currently in China. Dai Yi (2014) proposed a new teacher training model of using cloud media to promote the integration of training, research and application: urban and rural teachers' teaching research and the application led by teachers' autonomous learning based on the project Grow Up with Excellent Teachers ${ }^{[20]}$. Li Caiyan (2015) built a cloud video interactive system based on the current situation and level of English teaching in rural areas, through which she realized the application of cloud video in the urban and rural interactive English classroom and studied the interactive teaching mode of English lessons based on cloud video in rural areas ${ }^{[21]}$. Given the lack of systematic theoretical research and practical guidance on teacher's online training, Ding Dandan (2014) designed the teachers' online research community based on cloud services and carried out the application practice. However, the platform was in the trial operation stage. Only a few people participate in its evaluation. The lack of application in large scale also leads to the lack of test and verification of the organization and management mode.

\section{Introduction to Guangdong Education Cloud}

\section{Background of Guangdong Education Cloud}

The new generation of information technology represented by Cloud Computing, Big Data, Mobile Internet and Internet of Things has become the focus of national strategic emerging industry. It brings new opportunities to solve the bottleneck problems in the development of Education informatization. In 2011, China started establishing the cloud service mode of the national education . Guangdong

Education Cloud is one of the major actions of Education informatization in Guangdong Province ${ }^{[22]}$. Since 2014, as one of the first demonstration pilot areas of Guangdong Education Cloud, Zhuhai organized a project to explore the new mechanism and model of the integration of information technology and education, while constructing the Zhuhai pilot zone of Guangdong Education Cloud. The project aims to further improve primary and secondary school teachers' ability of using information technology to teach, inspire, demonstrate, guide, practice and feedback and to support the cooperation among students, explore the ability of construction, independent learning, and individualized development, thus to improve classroom teaching and learning. The project can also improve the capability of teachers to use Guangdong Education Cloud platform to demonstrate, comunicate and cooperate in teaching and learning. It aims to get new breakthrough in the integration of information technology and education.

\section{Main function of Guangdong Education Cloud Streaming}

Guangdong Education Cloud Streaming provides open, interoperable, and scalable educational video cloud services. It supports multi-terminal and multi-mode access and integrates teaching and research broadcast equipment/environment. It supports real-time interactive live classroom, teacher online classroom, online training, collaborative research and other typical applications. It is made up of three parts: Cloud Streaming Platform, Grow Up with Excellent Teachers and Interactive Online Courses. Through the mass streaming media cloud service, it promotes the innovation of teacher training model, improves the sharing of quality education resources, as well as the fairness of education.

\section{Cloud Streaming Platform}

Cloud Streaming Platform integrates third party platform services, including Guangdong education video web, Zhuhai education video resources platform, regional video education platform and educational video library, etc. It is able to achieve cloud encoding, transcoding, slice, live, virtual 
broadcast, shift, on demand, interactive collaboration, stream adaptive multi terminal cloud distribution. It can offer distributed cloud storage service for educational videos, and carry out live classroom, courier classroom, online collaborative education project management and content management.

Online Interactive Courses

Online Interactive Courses offers online real-time interaction and online learning support, learning management, learning content management, the classroom real-time broadcast, video-on-demand and online courses learning, together with web conferencing, electronic whiteboards, desktop sharing, collaborative editing service, etc.. Among these functions, online real-time interaction and online learning support service can provide highly experiential and available learning environment.

Grow Up with Excellent Teachers

Grow Up with Excellent Teachers offers four kinds of courses: synchronous course, excellent course, live classroom and interactive classroom. Synchronous course provides excellent teachers' videos of the knowledge points in the textbook to support the application of teachers and students. Excellent Courses provides users with high-quality videos which organize instant videos, leading videos for the user to observe. Live classroom provides classroom video broadcast service. It convergences Elite open class, teachers' interactive activities through the automatic recording system in schools and regions. Interactive classroom provides users with personalized, targeted real-time video on demand services, and supports distant real-time exchange, interaction and discussion among teachers and students

\section{New Models of Teacher Training based on Cloud Streaming Media}

\section{The Individual Training Model Based on the Observation of Teaching Video}

\section{Scope of application}

The model applies to teachers' extensive individual training. The trainees can use a variety of learning terminals such as PC and iPad, to observe and learn the lesson at any time anywhere.

Mode

Guangdong Education Cloud effectively integrates the Basic Education Resources Net of Guangdong and the Famous Teachers' Online Classroom in Guangdong province. It gathers massive quality resources, to solve the problem of the lack of excellent resources and the low availability of quality resources. The platform provides informative teaching capability training courses, informational leadership training courses and other resources. Resources are mainly micro video which are characterized by shortness, fastness and fineness. The special resources are integrated with different granularity, different teaching situations and teaching problems. This can enhance teachers' situational learning, thus promote effective and efficient teacher learning. Teachers use various types of terminals to carry out research anytime, anywhere and improve individual cognition level and practical ability through lesson observation, comment, share experiences, view experts' evaluation and reflection in practice etc. 


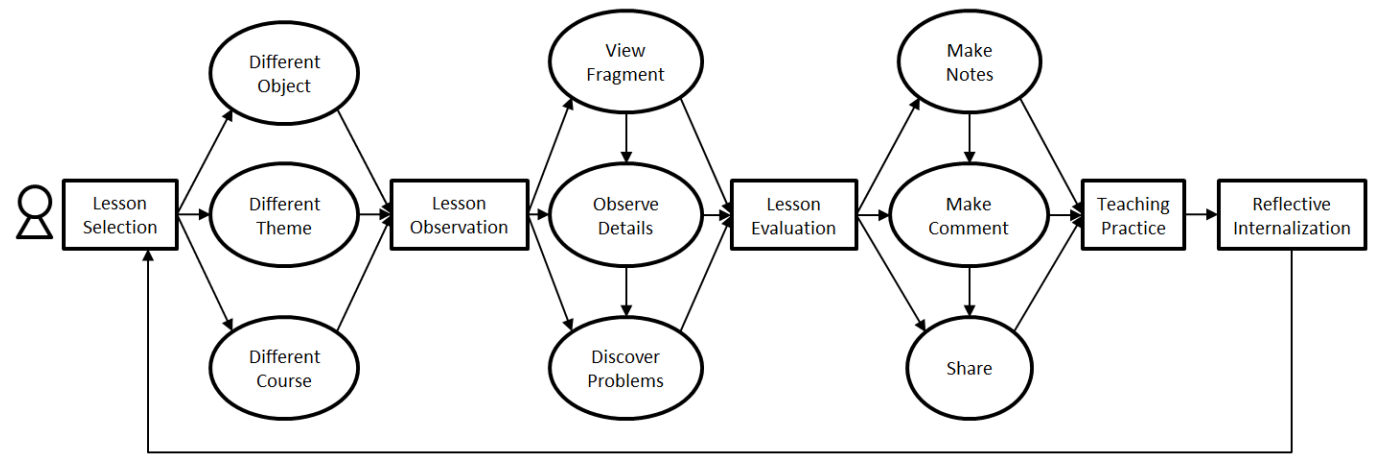

Fig.1 The Individual Training Model Based on the Observation of Teaching Video

\section{Application effect}

The teachers can get different results by watching different teaching videos. When the teachers watched their own videos, their focus switched from classroom management to teaching. When teachers watch other teachers' videos, they learn new teaching strategies to deal with the same teaching content or problems, and they can better understand the students' ideas in the classroom. When a teacher watches experts' video and writes teaching reflection, he/she is understanding of the teaching practice of expert teachers in-depth through indirect learning.

\section{The Group Training Model Based on Teaching Video Analysis}

\section{Scope of application}

The teachers of the same teaching and research office adopt the way of homogeneous grouping or heterogeneous grouping to form clubs. Homogeneous groups will have the teachers from the same or similar major background. It is suitable for the analysis of the content of the subject teaching. Heterogeneous groups contain teachers from various disciplines. These groups are suitable for the analysis of general teaching methods, information technology and curriculum integration.

\section{Mode}

Teacher groups regularly carry out face to face video exchange as video clubs. Teacher groups diagnosis and analysis video lesson section based on their own teaching experience, related scale or tools. By sharing their views, the group realized the reflection, internalization and innovation of knowledge in the exchange, sharing and collision. Video clubs can better reflect the way to provide social support for teacher training through group interaction.

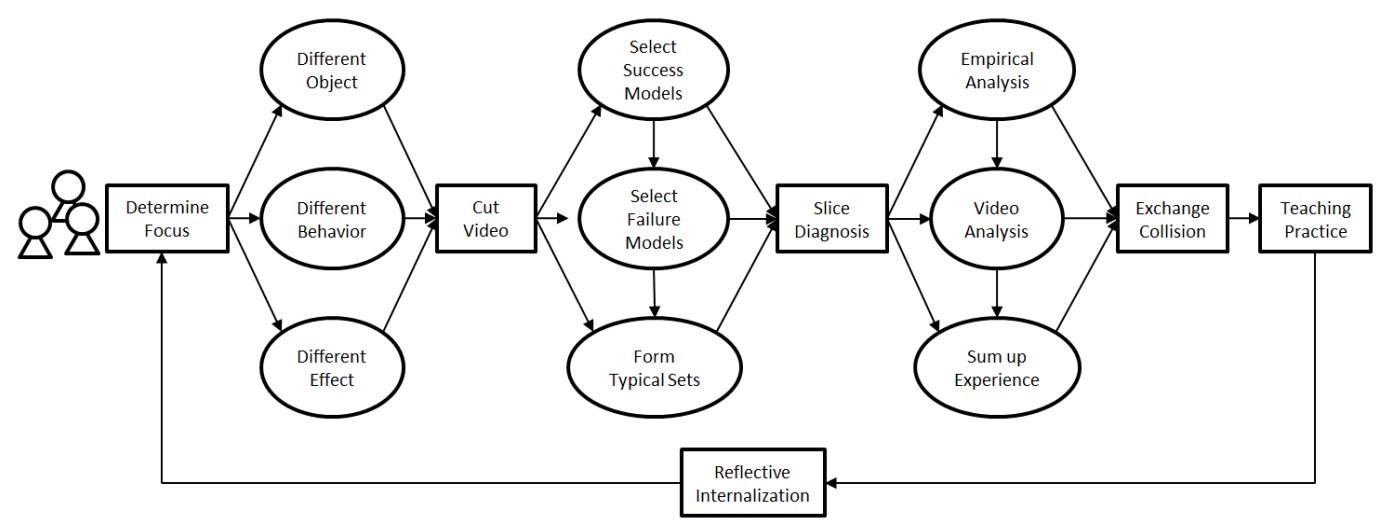

Fig.2 The Group Training Model Based on Teaching Video Analysis 


\section{Application effect}

Teaching video analysis is the reflection and evaluation to a series of issues, including the knowledge view, curriculum view, teachers' education philosophy, and the choice and usage of strategy. Teachers in different stages of professional development can review on the same teaching video from different perspectives. This process is beneficial to enhancing the teachers' professional insight and thinking level of teaching, that is, the ability to observe and explain the key features of the classroom practice. In order to carry out the video analysis in the form of the club, the teachers should have some experience in video analysis, so it is necessary to carry out the relevant knowledge and skills training before the group training.

\section{The Interactive Training Model Based on Online Project Learning}

\section{Scope of application}

The model is applicable to teacher groups from the same school, different schools or different regions. In this model, teachers can carry out the same course heterogeneous or distance teaching and research activities.

\section{Mode}

The online teaching and research of the same course heterogeneous is a typical application of online project learning. Teachers from different regions or schools teach the same section of the teaching content. They make instructional designs according to the students' reality, the existing teaching conditions and their own characteristics, and record video lessons. And then teachers put the different video lessons on the online project learning platform. Distant experts, teaching and research staff guide discussion, make comments through real time audio, video and text together. Teachers complete the teaching observation, resource sharing, and participate in interactive communication through group discussion or vote. Teachers compare different lessons for the advantages and disadvantages, and deeply understand the "difference" and the "similarity", so as to reflect their own instructional design. This process can be recorded for teachers to view at any time.

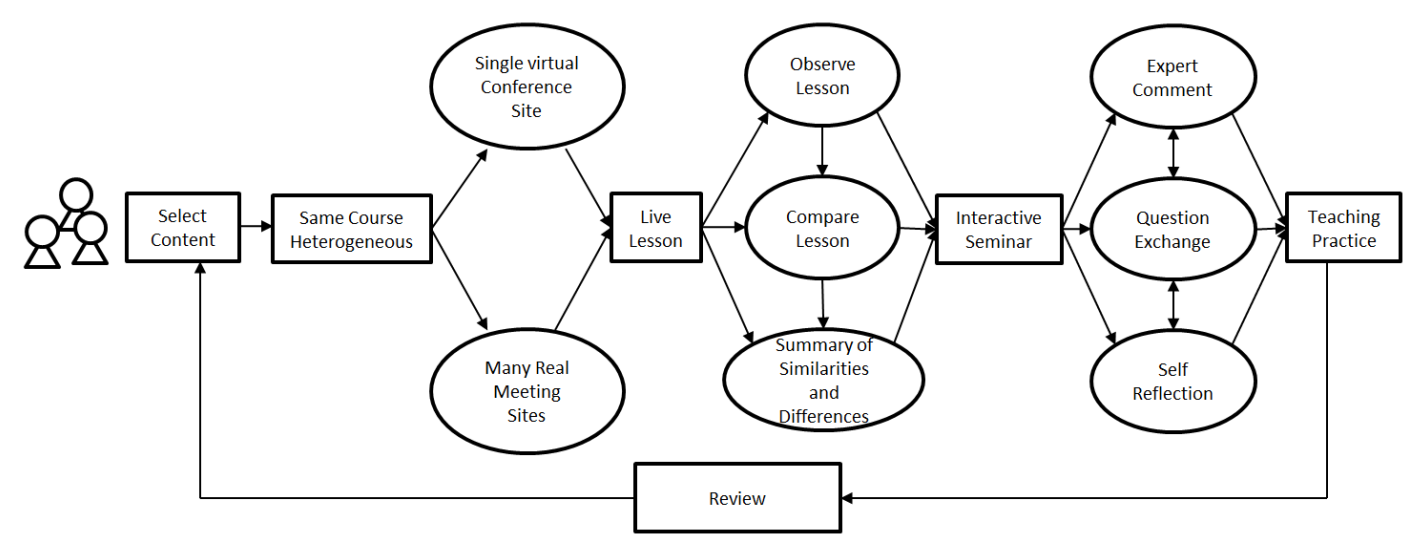

Fig.3 The Interactive Training Model Based on Online Project Learning / Interactive Teaching and Research

\section{Application effect}

The online teaching and research of Same Course Different Structure is a new form of education research, which carries on the instruction, research, communication, exchange and training of education and teaching based on the Adobe Connect meeting room. This form has the characteristics of being non-linear, non-structured, interactive, and can achieve the full participation of the teaching and research activities and a wide range of frequent communication. Teachers can participate in the teaching and research activities on the internet from different angles and at different levels according to individual needs and their teaching experience. This model can improve teachers' participation 
consciousness, and has strong pertinence and comparison operation capability. This model is benefitial for lesson-drive group discussion on curriculum standards, curriculum theory, the new teaching material, teaching experience, and realize resources sharing of the information department, library of courseware, test questions library, and teaching design.

\section{The Urban and Rural Linkage Training Model Based on Service Sharing}

\section{Scope of application}

The model is suitable for the teaching and research of urban and rural teachers in the cloud environment. This model uses urban quality teacher resources to help rural teachers to improve the overall quality, and to reduce the imbalance between urban and rural education information resources and quality teachers resources allocation imbalance.

\section{Mode}

Guangdong Education Cloud Platform gathers the outstanding video resources from all the experimental areas to support a wide range of application of live classroom, special delivery classroom and famous teacher online classroom. At present, 15 Zhuhai experimental schools have built up 35 cloud classrooms, equipped with remote interactive broadcasting system and online training platform. Teachers can use the platform to achieve one-way, two-way, multi direction online teaching and research activities. Teachers can watch the open class and live lessons of other experimental schools. Teachers can communicate with the audio or text through the interactive system to realize the linkage training between urban and rural teachers based on service sharing.

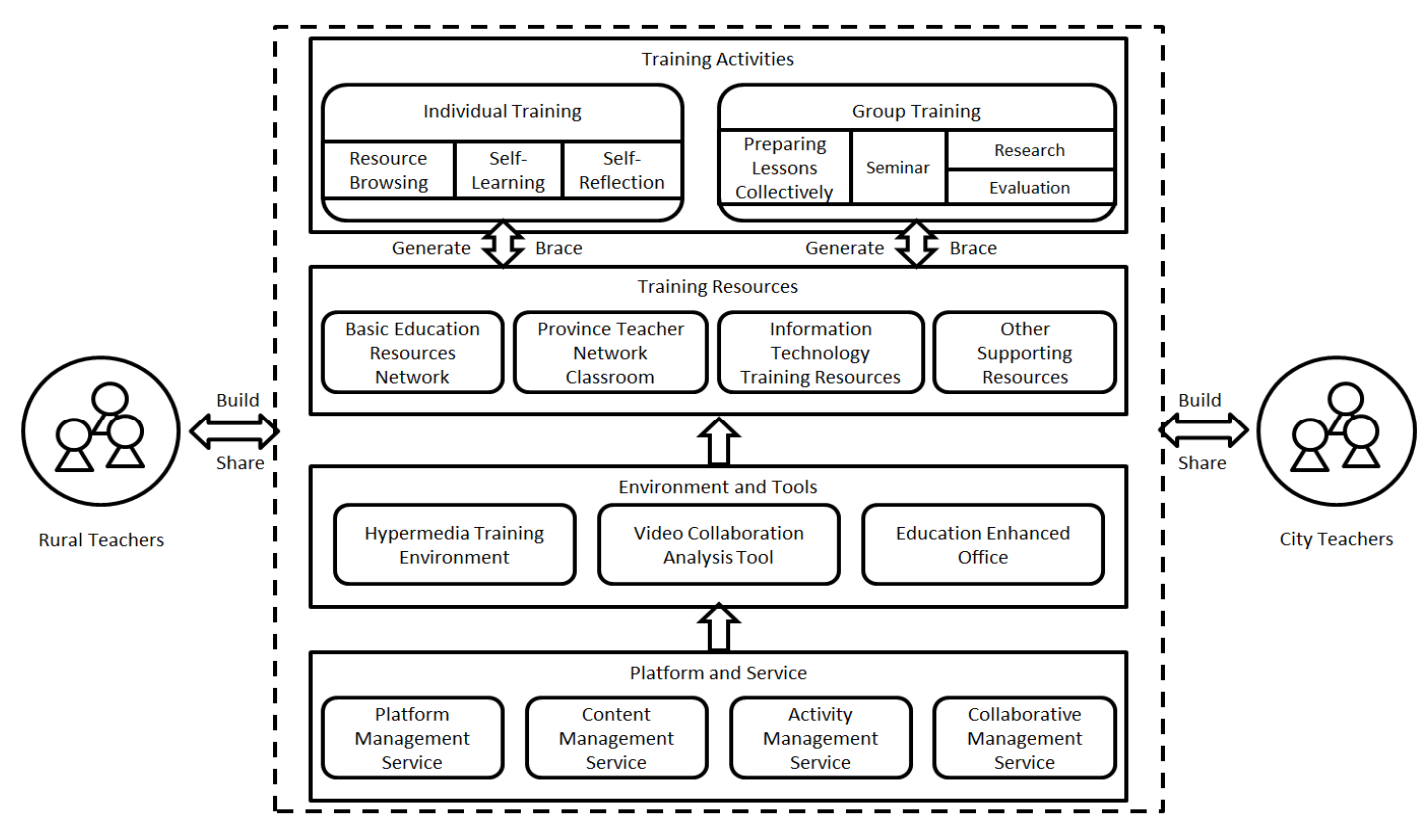

Fig.4 The Urban and Rural Linkage Training Model Based on Service Sharing

\section{Application effect}

To some extent, traditional network realizes the fairness of education information resources accessibility, but most teachers' synergy is only simple resource sharing in the range of professional knowledge.It did not combine with teaching practice, belonged to the static study and was lack of high quality support services and interaction. Urban and rural teachers' collaborative research based on service sharing can alleviate the lack of educational information resources in rural schools, and change the awkward situation of rural teachers' resources. 


\section{The Experiential School-based Training Model Based on Guangdong Education Cloud Classroom}

\section{Scope of application}

The model is applied to the school based teacher training. It is designed to improve the level of teaching and teaching ability of teachers based on the need and policy of the school.

\section{Mode}

Guangdong Education Cloud provides a strong school-based research platform, massive high-quality resources, as well as tools and software used in developing school-based training courses. In addition, teacher trainees equipped with learning terminals like PC, iPad take the experiential training using the functions of evaluation management, curriculum management, video distribution, online interaction, online evaluation, and data acquisition function in Guangdong Education Cloud Classroom. Experiential training adopts the multi-sensory learning methods, such as group discussion, scenario activity, role play, homework and so on, so that learners can obtain experience through their own experience. Training activities complete the perceptual to the rational rise, and back to the practice of teaching through direct action, experience, experience sharing, summary and application promotion.

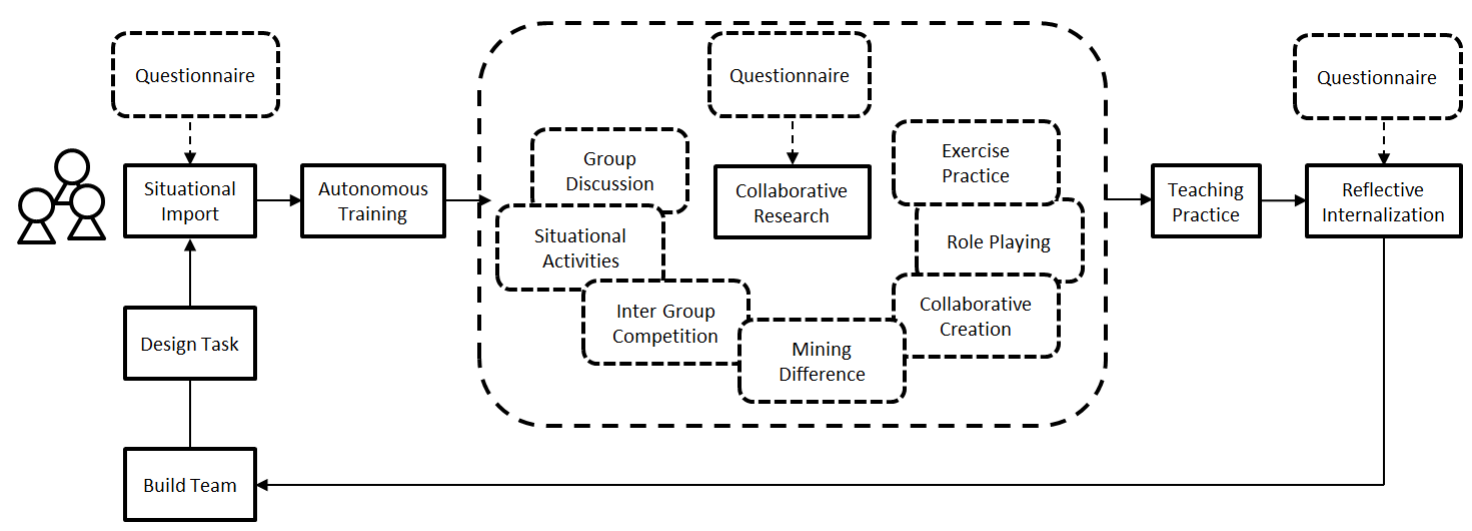

Fig.5 The Experiential School-based Training Model Based on Guangdong Education Cloud Classroom

\section{Application effect}

School-based research is an effective way to adapt to the trend of the era, to deepen the reform of the curriculum and to realize the professional development of teachers. The current commonly used modes such as Come in and Go out Model and One-One Mentoring Model meet the needs of school-based training to a certain extent. But the idea the way are not at the same level. The advanced concept is not supported by advanced technology. The traditional mode has neglected teachers' education concept and education experience, so it can't meet the needs of the teacher's individual development and the training costs are large. It is difficult to continue. The experiential school-based training model based on Guangdong Education Cloud Classroom can promote research, teaching, learning through study. It can also improve the poor by the strong, expand the experience, thus to realize the common goal of development, and effectively promote the professional development of teachers.

\section{Conclusion}

Along with the development of video interactive technology, the video-based teacher training is a helpful attempt to promote information reform in teaching and researching field in the information age. Guangdong Education Cloud provides cloud video resources and video interactive services, combines real time streaming media and visual interaction to make large-scale, high quality, low cost and large range teacher training possible. It effectively supports the teacher's individual training, school-based 
research and cross regional online teaching and research activities. This paper carries out the pilot regional teacher information technology research and practice based on the Guangdong Education Cloud public service platform, then puts forward five new models of teacher training based on high quality video resources and interactive communication technology. These models have been widely used in practice, demonstration lead and radiation driven effect is obvious. However, Guangdong Education Cloud's potential is far more than this. How to use it to solve the problems in fairness of education, balanced development, multi-angle evaluation and the burden of teachers and students still need further exploration.

\section{References}

[1][6][14] Liu Haihua, Xu Xiaodong, Yang Fei. New development and Enlightenment of foreign teachers' learning research based on video[J]. e-EDUCATION RESEARCH, 2015(5):108

[2] Li Sansan, Xu Xiaodong, Yanggang. Research on Teachers' learning based on video[J].Educational Information Technology, 2014(6):47-51

[3] Lei Gang. Research on innovative teacher training based on the platform of video education [J]. Continue Education Research, 2011(2): 50-51

[4] Sun Mo. Teacher distance training based on classroom teaching video case [J]. Chinese Audio-Visual Education, 2011(4): 63-66

[5] Bao Jiansheng, Wang Jie, Gu Lingyuan. Focus class[M]. Shanghai: Shanghai Education Press, 2005

[7][8][15] Wang Mei. Using Video Research to Facilitate Teacher Learning and Professional

Development [J]. JOURNAL OF DISTANCE EDUCATION. 2011(6): 65-72

[9] Li Jing. The Video Research in Teachers' Professional Development [D]. Nanchang: Jiangxi

Normal University. 2012

[10] Sunzhong, Ma Yuhui. Research on the promotion of novice teachers' professional development by multi analysis of video case[J]. e-EDUCATION RESEARCH, 2013,(8):104-109

[11] Sherin, M. G. The development of teachers' professional vision in video clubs. In

R. Goldman, R. Pea, B. Barron \& S. J. Denny ( Eds. ), Video research in the learning sciences. Mahwah, New Jersey: Lawrence Erlbaum Associates, 2007: 383-395.

[12] Xu Xiaodong, Ning Yan, Li Sansan \& Lu dan. Research Progress and Issues of Teacher Learning and Learning Methods [J]. JOURNAL OF DISTANCE EDUCATION, 2011(5): 23-31

[13] Gu Shaoqin, Carmen P. Brysch \& Richard G. Boehm. A New Pathway: Video-Based Teacher Professional Development--A Model of Teacher professional Development Program in the Field of Geography in the United States [J]. GLOBAL EDUCATION, 2013(10): 86-94

[16] Tang Aiyan. Analysis on the feasibility of distance teaching in contact interpretation [J]. Journal of Chongqing University of Science and Technology (SOCIAL SCIENCE EDITION), 2010 (17)

[17] Gong Xuxiao, Shang Qun, Zhang Bei, Zhang Yang. Peking University: cloud video open a new model of teaching [J]. China education network, 2012:44-45

[18] He Dan. The value of using technology to promote the publicity of the case of Shaoxing educational video cloud construction [J]. Zhejiang education technology, 2014 (3): 44-46

[19] Wu Na. Polycom cloud video to help improve the efficiency of communication [N]. People's Posts and telecommunications, 2014

[20] Dai Yi, Wu Fan, Li Liangjing, Wang Dongqing. Research on Teachers' information technology training platform and application model under the cloud media [J]. Modern Educational Technology (9): 114-120

[21] Li Caiyan. An analysis of the interaction between urban and rural English Teaching in high school based on the cloud video [J]. Journal of Xiamen radio and Television University, 2015 (3): 31-34 [22] Xu Jun, Tang Lianzhang. Educational information in the era of cloud computing and data exploration and practice -- "Guangdong Education cloud program and demonstration project [J]. Information technology education, 2014 (11) 